\title{
The First Optically Active Molecular Electronic Wires
}

\author{
Yuliang Zhu, ${ }^{a}$ Nadine Gergel, ${ }^{b}$ Nabanita Majumdar, ${ }^{b}$ Lloyd. R. Harriott, ${ }^{b}$ John C. \\ Bean, ${ }^{b}$ and Lin $\mathrm{Pu}^{\star \mathrm{a}}$ \\ ${ }^{a}$ Department of Chemistry and ${ }^{b}$ Department of Electrical and Computer Engineering, University of \\ Virginia, Charlottesville, Virginia 22904-4319, U.S.A. \\ Email Address: lp6n@virginia.edu
}

\section{Experimentals}

General Data. Optical rotations were measured on a Jasco DIP-1000 digital polarimeter. NMR spectra were recorded on a Varian-300 MHz spectrometer. Chemical shifts were given in ppm relative to the internal reference $\mathrm{CDCl}_{3}(1 \mathrm{H}, 7.23 \mathrm{ppm}$; 13C, $77.23 \mathrm{ppm})$. Mass spectra were recorded on a LCQ Finnigan mass spectrometer by using APCI (Atmospheric Pressure Chemical Ionization). HPLC analyses were carried out on the Waters 600 instrument by using the Diacel Chiralcel OD column and eluting with $10 \% i$ $\mathrm{PrOH}$ in hexane at $1.0 \mathrm{~mL} / \mathrm{min}$ and were detected at $254 \mathrm{~nm}$ by the Waters 486 . UV-vis spectra were recorded on a Cary 5E UV-vis-NIR spectrophotometer. Fluorescence spectra were recorded on a Perkin-Elmer LS-50B luminescence. The excitation and emission slits were set at 2.5 and $3.5 \mathrm{~nm}$, respectively. The scan speed was set at 100 $\mathrm{nm} / \mathrm{min}$. 
Modified Preparation of (S)-6,6'-Dichloro-2,2'-diethoxy-1,1'-binaphthyl, (S)-4. To a solution of (S)-6,6'-dibromo-2,2'-diethoxy-1,1'-binaphthyl (7.5 g, $15 \mathrm{mmol}),(S)$-3, in THF $(80 \mathrm{~mL})$ was added a hexane solution of $\mathrm{n}-\mathrm{BuLi}(1.6 \mathrm{M}, 28 \mathrm{~mL}, 45 \mathrm{mmol})$ at $-78{ }^{\circ} \mathrm{C}$ under nitrogen. The reaction mixture was stirred for $30 \mathrm{~min}$ and then a solution of hexachloroethane $(3.53 \mathrm{~g}, 15 \mathrm{mmol})$ in THF $(10 \mathrm{~mL})$ was added. The reaction mixture was allowed to warm to room temperature over $12 \mathrm{~h}$ and quenched with water. The organic layer was washed with brine, and dried over $\mathrm{Na}_{2} \mathrm{SO}_{4}$. After evaporation of the solvents, the residue was purified by column chromatography on silica-gel using hexane/AcOEt (9/1) to afford $(S)-4$ in 98\% yield $(6.1 \mathrm{~g})$.

Preparation and characterization of $(S)-7$. To a mixture of $(S)-5(0.3 \mathrm{mmol}, 170.7 \mathrm{mg})$ and $6(0.66 \mathrm{mmol}, 116.3 \mathrm{mg})$ were added THF $(6 \mathrm{~mL})$ and $\mathrm{Et}_{3} \mathrm{~N}(9 \mathrm{~mL})$. After this solution was degassed by bubbling $\mathrm{N}_{2}$ through for $30 \mathrm{~min}, \mathrm{Pd}\left(\mathrm{PPh}_{3}\right)_{4}(50 \mathrm{mg})$ and $\mathrm{CuI}$ (15 mg) were added. The resulting mixture was heated at $70{ }^{\circ} \mathrm{C}$ for $24 \mathrm{~h}$ and was cooled to room temperature. Hexane was used to extract, and the organic layer was washed with $1 \mathrm{~N} \mathrm{HCl}$, brine, saturated $\mathrm{NaHCO}_{3}$, and brine. Evaporation of the solvent gave a yellow solid. Flash column chromatography on silica gel (eluent: hexane:ethyl acetate $=10: 1$ ) gave the desired compound $(S)-7$ as a pale yellow solid in $86 \%$ yield $(196 \mathrm{mg}) . \quad[\alpha]_{\mathrm{D}}$ $60.1\left(\mathrm{c}=1.0, \mathrm{CH}_{2} \mathrm{Cl}_{2}\right) . \quad{ }^{1} \mathrm{H} \mathrm{NMR}\left(\mathrm{CDCl}_{3}, 300 \mathrm{MHz}\right) \delta 1.11(\mathrm{t}, \mathrm{J}=6.9 \mathrm{~Hz}, 6 \mathrm{H}), 2.48(\mathrm{~s}$, 6 H), 4.09 (dd, J = 6.9, $13.8 \mathrm{~Hz}, 4 \mathrm{H}), 7.07$ (d, J = 9 Hz, 2 H), 7.22 (dd, J = 2.1, $9.0 \mathrm{~Hz}, 2$ $\mathrm{H}), 7.49(\mathrm{~m}, 4 \mathrm{H}), 7.72(\mathrm{~m}, 6 \mathrm{H}), 8.38(\mathrm{~d}, \mathrm{~J}=2.1 \mathrm{~Hz}, 2 \mathrm{H}) .{ }^{13} \mathrm{C} \mathrm{NMR}\left(\mathrm{CDCl}_{3}, 75 \mathrm{MHz}\right) \delta$ $15.12,30.61,65.38,88.78,94.48,120.32,121.39,124.37,125.34,127.50,128.09,128.85$, 130.02, 130.89, 132.38, 132.54, 134.65, 153.99, 193.65. UV $\left(\mathrm{CH}_{2} \mathrm{Cl}_{2}\right) \lambda_{\max }(\varepsilon) \mathrm{nm}: 244$ 
$\left(9.64 \times 10^{4}\right), 282\left(3.31 \times 10^{4}\right), 330\left(3.79 \times 10^{4}\right), 380\left(4.75 \times 10^{4}\right) . \mathrm{CD}\left(\mathrm{CH}_{2} \mathrm{Cl}_{2}\right)[\theta]\left(\lambda_{\max }\right.$, nm): $\quad-9.99 \times 10^{4}(237), 1.72 \times 10^{5}(253),-2.44 \times 10^{4}$ (353). Mass (APCI) for $\mathrm{C}_{44} \mathrm{H}_{32} \mathrm{Cl}_{2} \mathrm{O}_{4} \mathrm{~S}_{2}(\mathrm{~m} / \mathrm{z}): 758.3\left(\mathrm{M}^{+}\right)$. Anal. Calcd for $\mathrm{C}_{44} \mathrm{H}_{32} \mathrm{Cl}_{2} \mathrm{O}_{4} \mathrm{~S}_{2}$ : C, 69.56; H, 4.25. Found: $\mathrm{C}, 69.27 ; \mathrm{H}, 4.26$. For $(R)-7, \mathrm{CD}\left(\mathrm{CH}_{2} \mathrm{Cl}_{2}\right)[\theta]\left(\lambda_{\max }, \mathrm{nm}\right): 8.77 \times 10^{4}(237)$, $1.68 \times 10^{5}(253), 2.37 \times 10^{4}(352)$.

UV Absorption Data of 8. UV $\left(\mathrm{CH}_{2} \mathrm{Cl}_{2}\right) \lambda_{\max }(\varepsilon) \mathrm{nm}: 232\left(1.88 \times 10^{4}\right), 334\left(4.89 \times 10^{4}\right)$, $354\left(3.78 \times 10^{4}\right), 382\left(\mathrm{sh}, 0.51 \times 10^{4}\right)$. 
Comparison of the currents of the homochiral and heterochiral molecules.

\section{Median current vs molecule type}

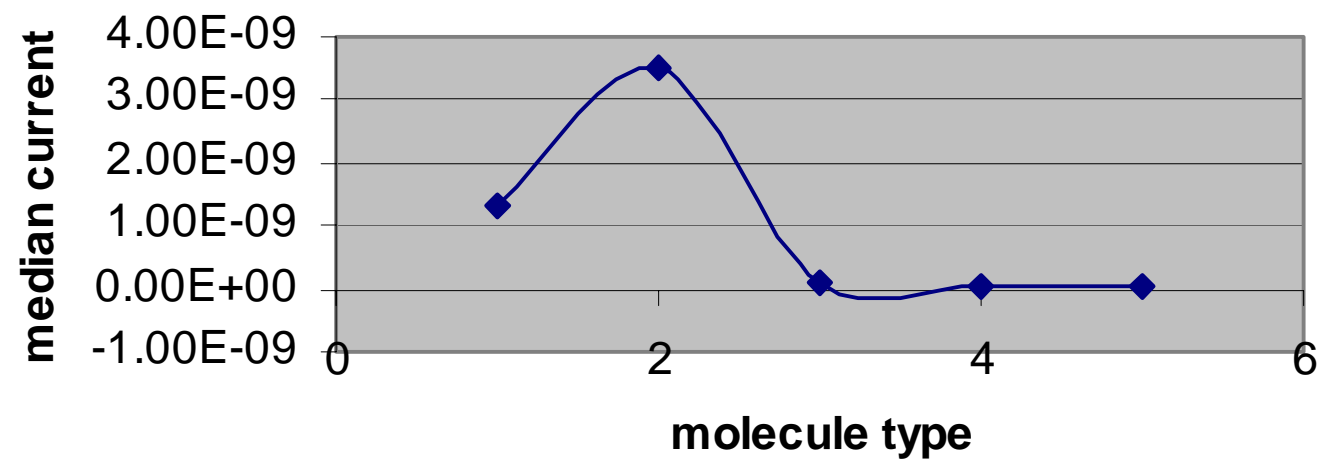

$1=$ pure $\mathrm{R}$

$2=$ pure $S$

$3=0.8 \mathrm{R}$

$4=0.5 \mathrm{R}$

$5=0.2 \mathrm{R}$

\section{Mean current vs molecule type}

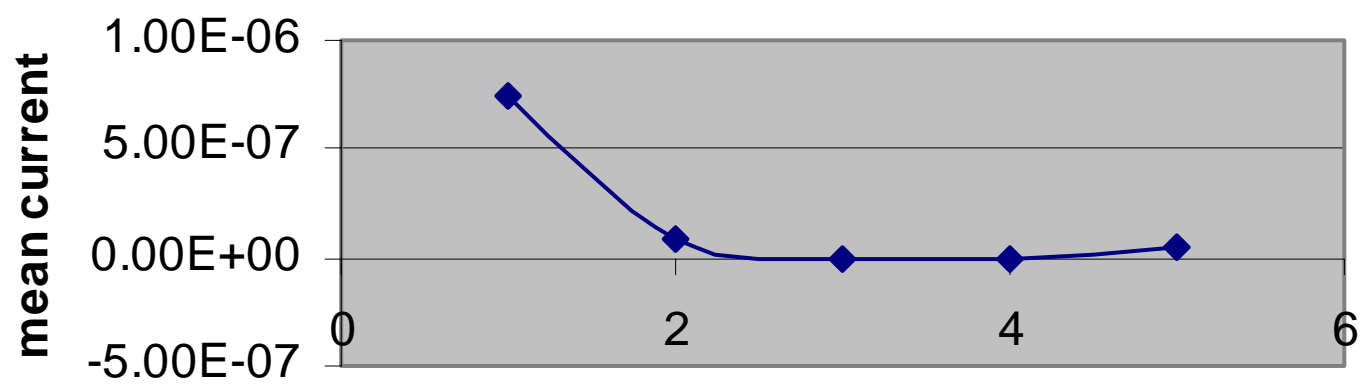

molecule type 
For $(R)-7$ : The median current value at $1.5 \mathrm{~V}$ was $1.3 \mathrm{nA}$, the mean current was $748 \mathrm{nA}$ and the overall current range was from $15 \mathrm{pA}$ to $9 \mathrm{uA}$.

For $(S)-7$ : The median current at $1.5 \mathrm{~V}$ was $3.5 \mathrm{nA}$, the mean current was $86 \mathrm{nA}$, and the overall range of current was from $300 \mathrm{pA}$ to $600 \mathrm{nA}$.

For $0.8 \mathrm{R}, 0.5 \mathrm{R}$ and $0.2 \mathrm{R}$ : The mean currents for the three compositions were $2 \mathrm{nA}$, $360 \mathrm{pA}$, and $48 \mathrm{nA}$ respectively. The total range of current was from single pAs to 380nA. 